\title{
Correlation between brain injury and dysphagia in adult patients with stroke
}

\author{
Maria Cristina de Alencar Nunes ${ }^{1}$, Ari Leon Jurkiewicz², Rosane Sampaio Santos ${ }^{3}$, Ana Maria Furkim ${ }^{4}$, Giselle Massi ${ }^{5}$, \\ Gisele Sant'Ana Pinto ${ }^{6}$, Marcos Christiano Lange'.
}

1) Speech Therapist. Student Doctorate in Internal Medicine from the Universidade Federal do Paraná (HC-UFPR). Professor of the Specialization Course on Dysphagia and Voice of the University Tuiuti do Paraná - Curitiba/PR.

2) Geriatrician. Doctor of Sciences from the UNIFESP / EPM. Professor of Masters and Doctorate in Communication Disorders at the University Tuiuti - Curitiba/PR.

3) Speech Therapist. Student Doctorate in Internal Medicine from the Universidade Federal do Paraná (HC-UFPR). Professor of Masters and Doctorate in Communication Disorders at the University Tuiuti - Curitiba/PR.

4) Speech Therapist. Doctor in Human Communication Disorders from the Federal University of Sao Paulo. Professor of Speech Pathology, Federal University of Santa Catarina/SC.

5) Speech Therapist. Doctor in Linguistics from the Universidade Federal do Paraná (UFPR). Professor of Masters and Doctorate in Communication Disorders at the University Tuiuti - Curitiba/PR.

6) Speech Therapist. Student Master in Internal Medicine from the Universidade Federal do Paraná (HC-UFPR) - Curitiba/PR.

7) Neurologist. Doctor in Internal Medicine from the Universidade Federal do Paraná (HC-UFPR) - Curitiba/PR.

Institution: Universidade Tuiutí do Paraná.

Curitiba/PR - Brazil.

Mailing address: Maria Cristina de Alencar Nunes - Travessa Capitão Clementino Paraná, 130 - Apt. 171 - Bloco B - Bairro Água Verde - Curitiba/PR - Brazil - Zip code 80620-180 - E-mail: mcrisnunes@yahoo.com.br

Article received in October 8, 2011. Article approved in May 8, 2012.

\section{SUMMARY}

Introduction: In the literature, the incidence of oropharyngeal dysphagia in patients with cerebrovascular accident (AVE) ranges $20-90 \%$. Some studies correlate the location of a stroke with dysphagia, while others do not.

Objective: To correlate brain injury with dysphagia in patients with stroke in relation to the type and location of stroke.

Method: A prospective study conducted at the Hospital de Clinicas with 30 stroke patients: 18 women and 12 men. All patients underwent clinical evaluation and swallowing nasolaryngofibroscopy $\left(\mathrm{FEES}^{\circledast}\right)$, and were divided based on the location of the injury: cerebral cortex, cerebellar cortex, subcortical areas, and type: hemorrhagic or transient ischemic.

Results: Of the 30 patients, 18 had ischemic stroke, 10 had hemorrhagic stroke, and 2 had transient stroke. Regarding the location, 10 lesions were in the cerebral cortex, 3 were in the cerebral and cerebellar cortices, 3 were in the cerebral cortex and subcortical areas, and 3 were in the cerebral and cerebellar cortices and subcortical areas. Cerebral cortex and subcortical area ischemic strokes predominated in the clinical evaluation of dysphagia. In $\mathrm{FEES}^{\oplus}$, decreased laryngeal sensitivity persisted following cerebral cortex and ischemic strokes. Waste in the pharyngeal recesses associated with epiglottic valleculae predominated in the piriform cortex in all lesion areas and in ischemic stroke. A patient with damage to the cerebral and cerebellar cortices from an ischemic stroke exhibited laryngeal penetration and tracheal aspiration of liquid and honey.

Conclusion: Dysphagia was prevalent when a lesion was located in the cerebral cortex and was of the ischemic type.

Keywords: stroke, deglutition disorders, ischemic attack, transient.

\section{INTRODUCTION}

It is estimated that vascularaccident (CVA) is responsible for approximately $10 \%$ of all deaths worldwide, with almost 6 million deaths mostly concentrated in poor countries (1).

In practice, speech pathologists work with various neurological diseases that cause changes in swallowing. These changes, called dysphagia, can lead to the patient's death because they lead to malnutrition, dehydration, tracheal aspiration, and recurrent pneumonia $(2,3)$. The speech pathologist deals specifically with oropharyngeal dysphagia, disorders affecting the oral and pharyngeal phases of swallowing.

Dysphagia is a swallowing disorder with symptoms that are characterized by specific changes at any step and/ or between the stages of swallowing dynamics, and can be congenital or acquired (2-5).

A follow-up of oropharyngeal dysphagia is absolutely necessary to the clinical evaluation procedure, and is carried out with videofluoroscopic assessment instruments and/or swallowing nasolaryngofibroscopy.

In the literature, the incidence of oropharyngeal dysphagia in stroke patients ranges 20-90\% (6-8). Some studies have correlated the location of stroke, i.e., cortical and brainstem (9), and brainstemand supratentorial(10), with the presence of dysphagia, while others have not $(8,11)$. The exact location of the stroke determines the extent of injury and neurological symptoms presented by each patient (12).

Identifying the location of the stroke with assistance from an audiologist will enable a more accurate pre- 
diagnosis of dysphagia and assist in evaluation and speech therapy to ensure treatment appropriate to each patient.

Thus, the objective of this study was to correlate the type and location of stroke in adult patients with dysphagia.

\section{METHOD}

The sample population comprised 30 patients affected by stroke confirmed by computed tomography, of which 18 (60.0\%) were female and 12 (40.0\%) were male. The patients' ages ranged 30-86 years, and the mean age and standard deviation was 60.6 (15.0) years.

Patients were divided into groups based on the location of the injury: cerebral cortex, cerebellar cortex, and subcortical areas, and the type of stroke: hemorrhagic or transient ischemic. Chart 1 details the distribution of the sample population in relation to the location and type of injury based on the variables age and sex.

The Research Ethics Committee of the Hospital de Clinicas, Federal University of Paraná (HC-UFPR), approved this study under No. 2169.064/2010-03. Subjects signed a consent form with the knowledge of the objectives, procedures, and responsibilities, as well as receiving answers to any questions regarding the survey.

Patients were evaluated within 48 hours of diagnosis of stroke and were responsive to the examination. Exclusion criteria were patients undergoing head and neck surgery or who had a previous diagnosis of structural abnormalities of the oropharyngolaryngeal tract, Glasgow Coma Scale level of consciousness (13) equal to or less than 11 , and clinically unstable.
The research proceeded in 2 stages consisting of functional and clinical assessments of swallowing nasolaryngofibroscopy.

In accordance with the data collection protocol, the first stage involved clinical evaluation in the institution. The subjects were observed for clinical signs of aspiration: cough, shortness of breath, and "wet" voice (14), and we evaluated their uptake of food, lip seal, preparation of the cake, subsequent extraoral exhaust, waste in the oral cavity, reflection cough, and hoarseness. For this assessment, subjects were offered 3 swallows: free drink, $10 \mathrm{~mL}$, and 5 $\mathrm{mL}$, for each food consistency (liquid, nectar, honey, and pudding) according to the standard ADA (15), with no interval between them. For solid food bites, the subjects were offered free saltine crackers. After clinical evaluation of swallowing function was applied to the Functional Food Scale: Functional Oral Intake Scale (FOIS ${ }^{\circledR}$ ) (16), where we assessed the level of acceptance of food, which ranged from level 1 (unable to receive oral diet) to level 7 (orally without restrictions), we carried out nasolaryngofibroscopy evaluation of swallowing $\left(\right.$ FEES $\left.^{\circledR}\right)$ (17).

FEES $^{\circledR}$ (17) was carried out according to the data protocol used in the institution. The offered consistencies followed the same methodology and standard ADA (15) used in the functional assessment of swallowing, with the addition of the inorganic dye aniline blue to contrast with the pinkish color of the mucosa.

The data collected during FEES $^{\circledR}$ (17) were tested by touch laryngeal sensitivity of distal fiberoptic vocal folds, arytenoid cartilage, and vestibular folds, allowing observation of the occurrence of glottal adduction and cough reflex, which was noted as present (normal or decreased) or absent. We observed

Chart I. Distribution of location and type of injury in relation to age and sex .

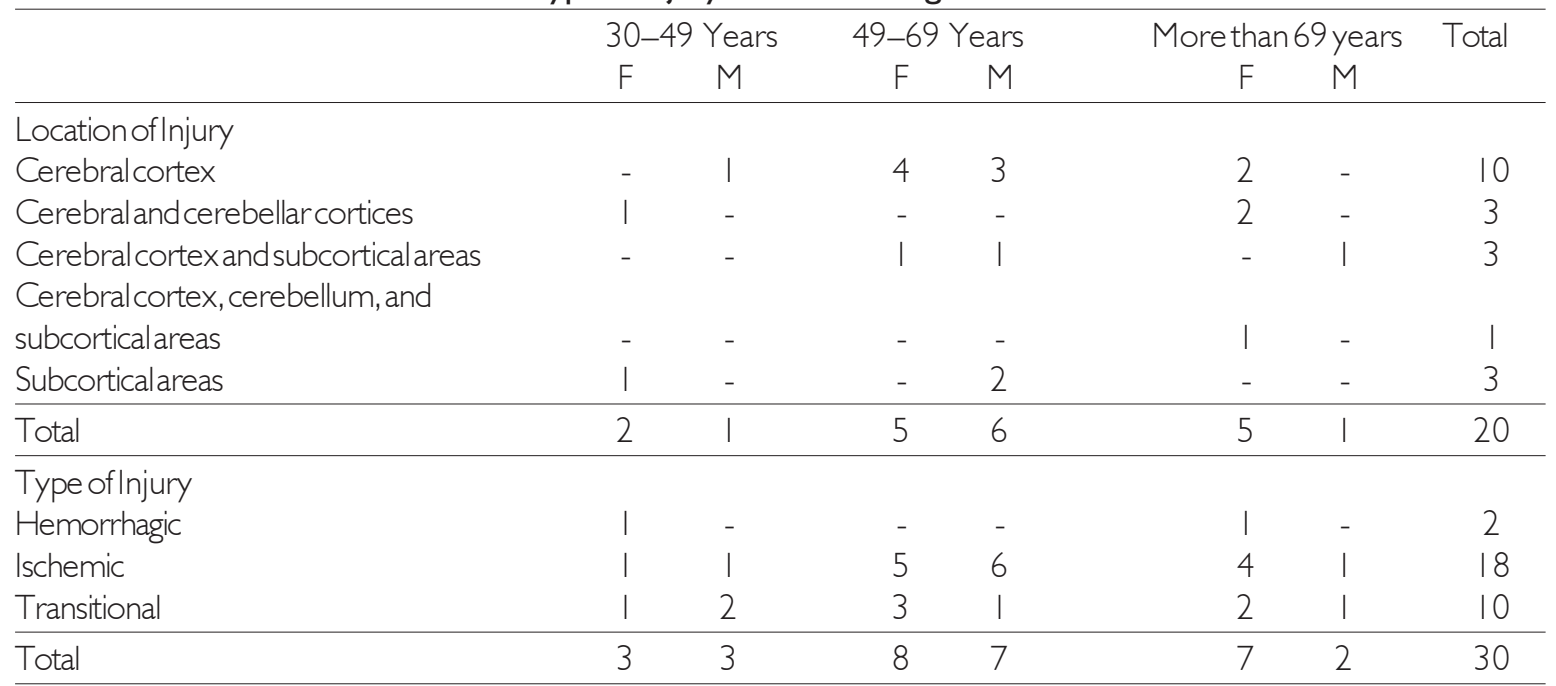

Source: The author. Note: $F=$ female, $M=$ male. 
the presence of exhaust intraoral posterior pharyngeal residue in the posterior pharyngeal wall, epiglottic valleculae, pyriform recess, pharyngeal clearance (number of swallows to clear), and laryngeal penetration or tracheal aspiration (with or without cough reflex), and applied the Severity Scale for Dysphagia: Penetration and Aspiration (18).

\section{RESULTS}

The findings of the clinical evaluation of swallowing function in relation to the location of the lesion in stroke patients are shown in Table 1 . Of 20 patients with ischemic and hemorrhagic strokes, 17 underwent evaluation with solid food, because 3 had no teeth. There was a prevalence of abnormalities in patients with lesions in the cerebral cortex and ischemic stroke.

Based on the location of the lesion (20 patients), FOIS $^{\oplus}$ (16) level 7 predominated in 14 patients; levels 1 and 5 were each recorded in 2 patients, and levels 3 and 6 were each recorded in 1 patient. Based on the type of injury (30 patients), FOIS ${ }^{\circledast}$ (16) level 7 predominated in 20 patients, followed by level 1 in 5 patients, level 5 in 3 patients, and levels 3 and 6 each in 1 patient. No patient scored levels 2 or 4 .

The FEES ${ }^{\circledR}$ (17) findings on laryngeal sensitivity in relation to the location and type of lesion are shown in Table 2.

The correlation between the location of the lesion and the subsequent intraoral escape in FEES ${ }^{\circledast}(17)$ based on food consistencies persisted in patients with lesions in the cerebral cortex and subcortical area for all food consistencies.

Table 3 shows the correlations between the location of the lesion and the locations of waste in pharyngeal FEES $^{\circledR}$ (17) based on food consistencies. There was a predominance of pharyngeal residue in epiglottic valleculae associated with pyriform recesses for all food consistencies, which did not occur with lesions located in the cerebral cortex, subcortical and cerebral cortices, and cerebellar cortex and subcortical areas.

Bleaching of pharyngeal residue in relation to the location and type of lesion with food consistencies is shown in Table 4.

The findings of laryngeal penetration and tracheal aspiration on FEES ${ }^{\oplus}$ (17) in relation to lesion location and food consistency are shown in Table 5 and that related with the type of injury in Table 6.
Regarding Severity Scale: Penetration and Aspiration (18) scoring based on the location of the lesion, 14 patients scored 1 point, while 3 patients scored 7 points, 2 patients scored 8 points, and 1 patient scored 2 points. When the type of stroke was considered, 19 patients scored 1 point, 5 patients scored 8 points, 4 patients scored 7 points, and 1 patient each scored 4 and 2 points on the Scale.

Severity Scale: Penetration and Aspiration (18) scores of 3,5 , and 6 points were not observed in this study. Only one patient presented with a TIA score of 4 .

\section{DISCUSSION}

All patients had good awareness levels, presenting Glasgow Coma Scale (13) levels greater than or equal to 12. Other authors have pointed out that preserved cognition decreases the risk of aspiration pneumonia $(19,20)$.

In this study, there were cases of TIA-related functional dysphagia in clinical and instrumental assessments of swallowing, which was not found in the literature.

In the TAC results, 10 patients presented with TIA within normal limits. Other authors have stressed that TIAs last less than 24 hours and lead to symptoms that usually resolve within hours (21). Therefore, patients with TIA who underwent the clinical and instrumental functional swallowing evaluation before 48 hours should not develop dysphagia. In this study, patients were assessed 24 hours after stroke because the HC-UFPR is not an open-door hospital, and a patient is referred from a clinic.

The change in swallowing after a TIA may be related to "transient dysphagia" occurring in the acute phase and during the regression of symptoms in this type of stroke.

It is essential that the interdisciplinary team focuses on the risks of dysphagia in patients after TIA and the importance of speech therapy referral for clinical evaluation of swallowing function before the patient is discharged. The post-TIA patients in this study only remained under observation in the emergency room without requiring hospitalization.

There were no changes in both oral and pharyngeal phases in the clinical evaluation of swallowing function in patients with AVEH, stroke, and TIA. Dysphagia was observed in all food consistencies, i.e., liquid, nectar, honey, pudding, and solids. In 1997, it was found that 96\% of adults with stroke exhibited disorders in the oral phase and $80 \%$ of adults with stroke exhibited disorders in the 
Table I. Distribution of clinical evaluation of swallowing test findings in relation to location of injury.

\begin{tabular}{|c|c|c|c|c|c|c|c|c|c|c|}
\hline \multirow[t]{3}{*}{ Location of Injury } & \multicolumn{2}{|c|}{ Liquid } & \multirow{2}{*}{\multicolumn{2}{|c|}{$\begin{array}{c}\text { Nectar } \\
\text { Capture }\end{array}$}} & \multirow{2}{*}{\multicolumn{2}{|c|}{$\begin{array}{l}\text { Honey } \\
\text { of Cake }\end{array}$}} & \multicolumn{2}{|c|}{ Pudding } & \multicolumn{2}{|c|}{ Solid } \\
\hline & & & & & & & & & & \\
\hline & E & $\mathrm{NE}$ & E & NE & E & $\mathrm{NE}$ & E & $\mathrm{NE}$ & E & $\mathrm{NE}$ \\
\hline Cerebralcortex & 10 & - & 10 & - & 10 & - & II & - & 10 & - \\
\hline Cerebraland cerebellarcortices & 2 & I & 2 & । & 2 & I & 2 & I & 2 & - \\
\hline Cerebral cortexand subcorticalareas & I & 2 & I & 2 & I & 2 & I & I & I & - \\
\hline Cerebral cortex, cerebellum, and subcorticalareas & I & - & I & - & I & - & I & - & I & - \\
\hline \multirow[t]{3}{*}{ Subcorticalarea } & I & 2 & 2 & I & 2 & I & 2 & I & 2 & I \\
\hline & \multicolumn{8}{|c|}{ Lip Seal } & & \\
\hline & $\mathrm{E}$ & $\mathrm{NE}$ & E & $\mathrm{NE}$ & $\mathrm{E}$ & $\mathrm{NE}$ & E & $\mathrm{NE}$ & E & $\mathrm{NE}$ \\
\hline Cerebralcortex & 10 & - & 10 & - & 10 & - & II & - & 10 & - \\
\hline Cerebraland cerebellarcortices & 2 & । & 2 & । & 2 & I & 2 & I & 2 & - \\
\hline Cerebral cortexand subcorticalareas & - & 3 & - & 3 & - & 3 & - & 2 & - & । \\
\hline Cerebral cortex, cerebellum, and subcortical areas & | & - & । & - & 1 & - & I & - & I & - \\
\hline \multirow[t]{3}{*}{ Subcorticalareas } & 2 & I & 2 & I & 2 & । & 2 & । & 2 & । \\
\hline & \multicolumn{8}{|c|}{ Preparation of Cake } & & \\
\hline & E & $\mathrm{NE}$ & E & $\mathrm{NE}$ & E & $\mathrm{NE}$ & E & $\mathrm{NE}$ & E & $\mathrm{NE}$ \\
\hline Cerebralcortex & 10 & - & 10 & - & 10 & - & II & - & 9 & I \\
\hline Cerebraland cerebellarcortices & 3 & - & 3 & - & 3 & - & 3 & - & 2 & - \\
\hline Cerebral cortexand subcorticalareas & - & 3 & - & 3 & - & 3 & - & 2 & - & I \\
\hline Cerebral cortex, cerebellum, and subcorticalareas & । & - & । & - & । & - & l & - & । & - \\
\hline Subcorticalareas & 2 & I & 2 & I & 2 & । & 2 & I & 2 & I \\
\hline
\end{tabular}

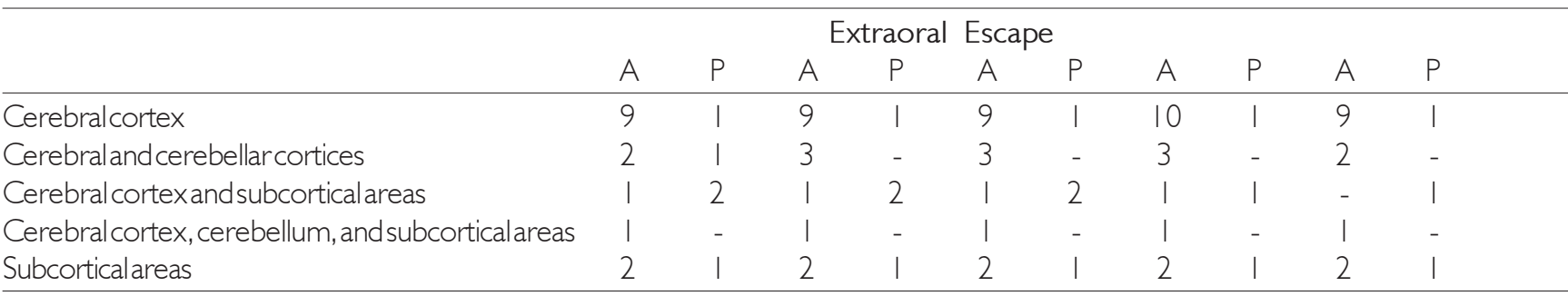

Subcorticalareas

Waste in Oral Cavity

Cerebralcortex

Cerebraland cerebellarcortices

Cerebral cortexand subcortical areas

Cerebral cortex, cerebellum, and subcorticalareas

Subcorticalareas

$\begin{array}{cccccccccc}A & P & A & P & A & P & A & P & A & P \\ 10 & - & 10 & - & 10 & - & 11 & - & 10 & - \\ 2 & 1 & 2 & 1 & 2 & 1 & 2 & 1 & 2 & - \\ - & 3 & - & 3 & - & 3 & - & 2 & - & 1 \\ 1 & - & 1 & - & 1 & - & 1 & - & 1 & - \\ 3 & - & 3 & - & 3 & - & 3 & - & 3 & -\end{array}$

\section{Cough Reflex}

Cerebral cortex

Cerebraland cerebellarcortices

Cerebral cortexand subcorticalareas

Cerebral cortex, cerebellum, and subcortical areas

Subcorticalareas

$\begin{array}{cccccccccc}A & P & A & P & A & P & A & P & A & P \\ 10 & - & 10 & - & 10 & - & 11 & - & 10 & - \\ 2 & 1 & 3 & - & 3 & - & 3 & - & 2 & - \\ 1 & 2 & 1 & 2 & 1 & 2 & 1 & 1 & - & 1 \\ 1 & - & 1 & - & 1 & - & 1 & - & 1 & - \\ 2 & 1 & 2 & 1 & 2 & 1 & 2 & 1 & 2 & 1\end{array}$

Hawk

Cerebralcortex

Cerebraland cerebellarcortices

Cerebral cortexand subcortical areas

Cerebral cortex, cerebellum, and subcortical areas

Subcorticalareas

$\begin{array}{cccccccccc}A & P & A & P & A & P & A & P & A & P \\ 10 & - & 10 & - & 10 & - & 11 & - & 10 & - \\ 3 & - & 2 & 1 & 3 & - & 3 & - & 2 & - \\ 3 & - & 3 & - & 2 & 1 & 2 & 1 & 1 & - \\ 1 & - & 1 & - & 1 & - & 1 & - & 1 & - \\ 3 & - & 3 & - & 3 & - & 3 & - & 3 & -\end{array}$

Source: The author. Note: $\mathrm{NE}=$ not effective, $\mathrm{E}=$ efficient, $\mathrm{A}=$ absent, $\mathrm{P}=$ present. 
Table 2. Distribution of laryngeal sensitivity in relation to location and type of injury.

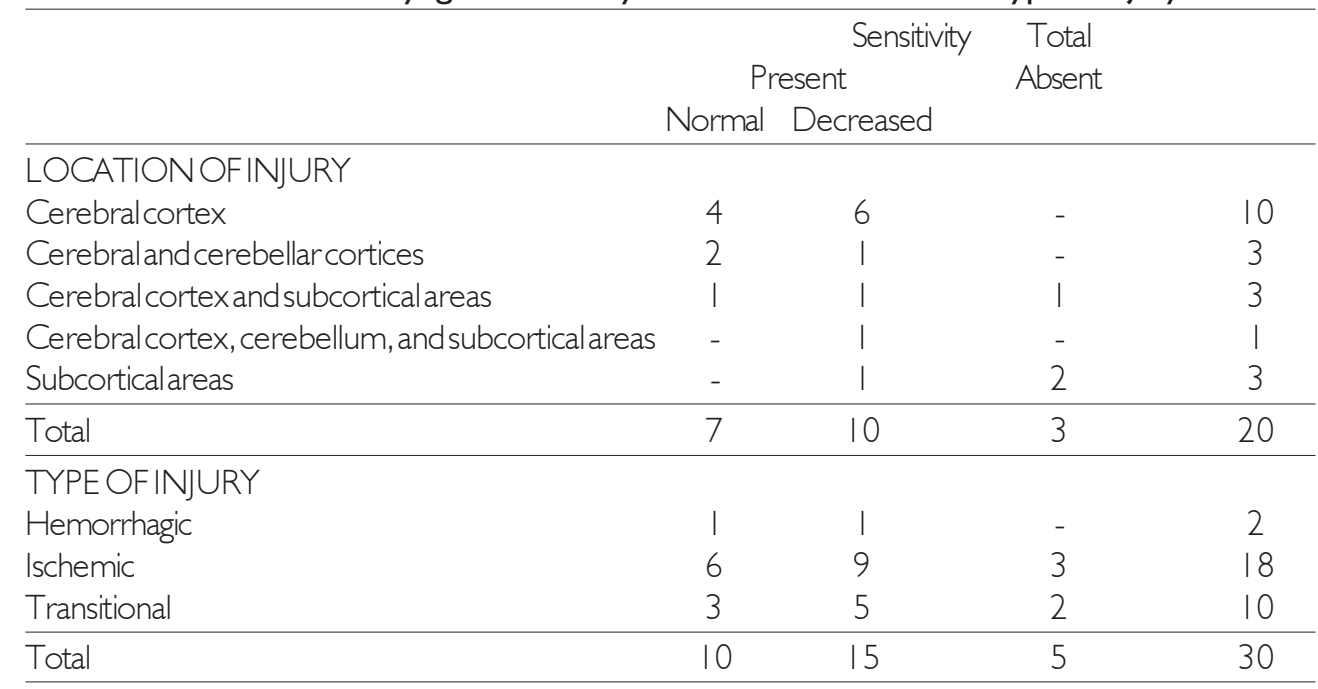

Source: The author

Table 3. Pharyngeal waste distribution in relation with food consistency and location of second injury .

\begin{tabular}{|c|c|c|c|c|c|}
\hline & $\begin{array}{l}\text { Cerebral } \\
\text { cortex }\end{array}$ & $\begin{array}{l}\text { Cerebraland } \\
\text { cerebellarcortices }\end{array}$ & $\begin{array}{c}\text { Location of Injury } \\
\text { Cerebral cortex } \\
\text { andsubcortical } \\
\text { areas }\end{array}$ & $\begin{array}{l}\text { Cerebral cortex, } \\
\text { cerebellum, and } \\
\text { subcorticalareas }\end{array}$ & $\begin{array}{l}\text { Subcortical } \\
\text { areas }\end{array}$ \\
\hline \multicolumn{6}{|l|}{ Waste pharyngealliquid } \\
\hline Absent & 5 & I & 3 & । & । \\
\hline Epiglottic valleculae & I & - & - & - & - \\
\hline Pyriform recesses & - & I & - & - & - \\
\hline Epiglottic valleculae + pyriform recesses & 4 & । & - & - & 2 \\
\hline $\begin{array}{l}\text { Pyriform recesses + posterior pharyngeal wall } \\
\text { Epiglottic valleculae + pyriform recesses + }\end{array}$ & - & - & - & - & - \\
\hline posterior pharyngeal wall & - & - & - & - & - \\
\hline \multicolumn{6}{|l|}{ Waste pharyngealnectar } \\
\hline Absent & 4 & 1 & 3 & I & - \\
\hline Epiglottic valleculae & । & - & - & - & - \\
\hline Pyriform recesses & 1 & I & - & - & - \\
\hline Epiglottic valleculae + pyriform recesses & 4 & i & - & - & 3 \\
\hline Pyriform recesses + posterior pharyngeal wall & - & - & - & - & - \\
\hline $\begin{array}{l}\text { Epiglottic valleculae + pyriform recesses + } \\
\text { posterior pharyngeal wall }\end{array}$ & & - & & & \\
\hline \multicolumn{6}{|l|}{ Waste pharyngealhoney } \\
\hline Absent & 4 & । & 3 & । & - \\
\hline Epiglottic valleculae & - & - & - & - & - \\
\hline Pyriform recesses & । & । & - & - & - \\
\hline Epiglottic valleculae + pyriform recesses & 5 & । & - & - & 3 \\
\hline Pyriform recesses + posterior pharyngeal wall & - & - & - & - & - \\
\hline $\begin{array}{l}\text { Epiglottic valleculae + pyriform recesses + } \\
\text { posterior pharyngeal wall }\end{array}$ & - & - & - & - & \\
\hline \multicolumn{6}{|l|}{ Waste pharyngealpudding } \\
\hline Absent & 4 & - & 3 & । & । \\
\hline Epiglottic valleculae & I & - & - & - & - \\
\hline Pyriform recesses & I & I & - & - & - \\
\hline Epiglottic valleculae + pyriformrecesses & 4 & 2 & - & - & 2 \\
\hline $\begin{array}{l}\text { Pyriform recesses + posterior pharyngeal wall } \\
\text { Epiglottic valleculae + pyriform recesses + }\end{array}$ & - & - & - & - & - \\
\hline posterior pharyngeal wall & - & - & - & - & - \\
\hline
\end{tabular}

Source: The author 
Table 4. Whitening pharyngeal waste according to location and type of injury and food consistency .

\begin{tabular}{|c|c|c|c|c|c|c|c|c|}
\hline & \multicolumn{8}{|c|}{ Whitening PharyngealWaste } \\
\hline & \multicolumn{2}{|c|}{ Liquid } & \multicolumn{2}{|c|}{ Nectar } & \multicolumn{2}{|c|}{ Honey } & \multicolumn{2}{|c|}{ Pudding } \\
\hline & Yes & No & Yes & No & Yes & No & Yes & No \\
\hline \multicolumn{9}{|l|}{ LOCATIONOFINJURY } \\
\hline Cerebral cortex & 5 & - & 6 & - & 5 & | & 5 & । \\
\hline Cerebraland cerebellarcortices & 2 & - & 2 & - & 2 & - & 3 & - \\
\hline Cerebral cortexandsubcortical areas & - & - & - & - & - & - & - & - \\
\hline Cerebral cortex, cerebellum, and subcortical areas & - & - & - & - & - & - & - & - \\
\hline Subcorticalareas & - & 2 & । & 2 & । & 2 & - & 2 \\
\hline \multicolumn{9}{|l|}{ TYPE OF INJURY } \\
\hline Hemorrhagic & I & - & 1 & - & I & - & 2 & - \\
\hline Ischemic & 6 & 2 & 8 & 2 & 7 & 3 & 6 & 3 \\
\hline Transitional & 4 & 2 & 5 & I & 4 & 2 & 3 & 2 \\
\hline $\bar{P}$ & \multicolumn{2}{|c|}{0.7778} & \multicolumn{2}{|c|}{0.8182} & \multicolumn{2}{|c|}{0.7273} & \multicolumn{2}{|c|}{$0.509 \mid$} \\
\hline
\end{tabular}

Source: The author. Fisher's test at significance level of 0.05 .

Table 5. Laryngeal penetration and tracheal aspiration in relation to location of injury and food consistency.

\begin{tabular}{|c|c|c|c|c|c|c|c|c|c|c|}
\hline \multirow[b]{2}{*}{ LOCATIONOFINJURY } & \multicolumn{2}{|c|}{ Liquid } & \multicolumn{2}{|c|}{ Nectar } & \multicolumn{3}{|c|}{ Honey } & \multicolumn{3}{|c|}{ Pudding } \\
\hline & $\begin{array}{l}\text { Yes } \\
\text { CR I }\end{array}$ & ${ }_{N R}{ }^{\text {No }}$ & $\begin{array}{l}\text { Yes } \\
\text { CR }\end{array}$ & ${ }_{N R}{ }^{N o}$ & $\begin{array}{l}\text { Yes } \\
\text { CR }\end{array}$ & & Vo & $\begin{array}{l}\text { Yes } \\
\text { CR }\end{array}$ & & No \\
\hline & \multicolumn{10}{|c|}{ Laryngeal Penetration } \\
\hline Cerebralcortex & । & -9 & - & -10 & 2 & & 8 & 2 & - & 8 \\
\hline Cerebraland cerebellarcortices & । & -2 & - & -3 & - & - & 3 & - & - & 3 \\
\hline Cerebral cortexand subcorticalareas & - & -3 & - & -3 & - & - & 3 & - & - & 3 \\
\hline Cerebral cortex, cerebellum, and subcorticalareas & - & -1 & - & -1 & - & - & । & - & - & I \\
\hline \multirow[t]{2}{*}{ Subcorticalareas } & - & 12 & - & 12 & - & | & 2 & - & | & 2 \\
\hline & \multicolumn{10}{|c|}{ TrachealAspiration } \\
\hline Cerebralcortex & - & -10 & - & -10 & I & - & 9 & I & | & 8 \\
\hline Cerebraland cerebellarcortices & I & -2 & - & -3 & I & - & 2 & - & - & 3 \\
\hline Cerebral cortexand subcortical areas & - & -3 & - & -3 & - & - & 3 & - & - & 3 \\
\hline Cerebral cortex, cerebellum, and subcortical areas & - & -1 & - & -1 & - & - & I & - & - & I \\
\hline Subcorticalareas & - & | 2 & - & 12 & - & | & 2 & - & | & 2 \\
\hline
\end{tabular}

Source: The author. Note: $\mathrm{CR}=$ cough reflex, $\mathrm{NR}=$ no cough reflex

Table 6. Laryngeal penetration and tracheal aspiration regarding types of injury and FEES ${ }^{\circledR}$ food consistencies second in patients stroke.

\begin{tabular}{|c|c|c|c|c|}
\hline \multirow[b]{2}{*}{ TYPE OFSTROKE } & Liquid & Nectar & Honey & Pudding \\
\hline & $\begin{array}{l}\text { Yes No } \\
\text { CRNR }\end{array}$ & $\begin{array}{l}\text { Yes No } \\
\text { CRNR }\end{array}$ & $\begin{array}{l}\text { Yes No } \\
\text { CRNR }\end{array}$ & $\begin{array}{l}\text { Yes No } \\
\text { CRNR }\end{array}$ \\
\hline & \multicolumn{4}{|c|}{ LaryngealPenetration } \\
\hline Hemorrhagic stroke & $1-1$ & $-\quad-2$ & $-\quad-2$ & $-\quad-2$ \\
\hline Ischemicstroke & 1116 & -117 & 2115 & 1116 \\
\hline Transitional & 235 & -28 & 118 & -19 \\
\hline \multirow[t]{2}{*}{$P$} & 0,2982 & 0,8947 & 0,7158 & 0,7158 \\
\hline & \multicolumn{4}{|c|}{ TrachealAspiration } \\
\hline Hemorrhagicstroke & $-\quad-2$ & $-\quad-2$ & $1-1$ & $-\quad-2$ \\
\hline Ischemicstroke & 1116 & -117 & 1116 & 1215 \\
\hline Transitional & 136 & -28 & -19 & -19 \\
\hline $\bar{P}$ & 0,7553 & 0,8947 & 0,8947 & $0,7 \mid 58$ \\
\hline
\end{tabular}

Source: The author. Note: $\mathrm{CR}=$ cough reflex, $\mathrm{NR}=$ no cough reflex Fisher's test at significance level of 0.05 . 
oral and pharyngeal phases of swallowing and dysphagia (22); another author reported oral phase disorders and pharyngeal dysphagia for solid and liquid consistencies (23).

In the variables studied, such as the uptake of cake, lip seal, cake preparation, escape of extraoral waste in the oral cavity, throat clearing, and cough reflex, efficiency predominated when correlating all food consistencies and isolated locations in the cerebral cortex; cerebellar and cerebral cortices; the cerebellum, cerebral cortex, and subcortical areas; cerebral cortex, subcortical areas, and cerebellar cortices; and subcortical areas. No citation was found for clinical evaluation of swallowing in relation to functional food consistencies correlating with the location of the lesion in the cerebral cortex, cerebellar cortex, and subcorticalareas.

In the correlation between the type of injury with stroke, a similar FOIS ${ }^{\circledR}$ (16) score in the literature was identified only in a case study (24) of post-stroke patients, which recorded that FOIS ${ }^{\circledR}(16)$ score before speech therapy.

The diagnosis of dysphagia in this study increased after FEES ${ }^{\oplus}$ (17), agreeing with the findings of other authors (20). During the functional clinical evaluation of swallowing, we observed silent aspiration in some patients, and the speech therapist evaluator found that it was merely due to the instrumental assessment of swallowing.

There are no records in the literature that correlate laryngeal sensitivity to the location and type of lesion in patients with stroke, and authors have only reported reduced oropharyngeal sensitivity $(25,26)$.

There was a predominance of decreased laryngeal sensitivity in stroke in the cerebral cortex and in ischemic and transient strokes, as well as a lack of sensitivity without laryngeal cough reflex, i.e., silent aspiration was predominant in subcortical area strokes. Regardless of the location and type of injury, there was a predominance of decreased or absent laryngeal sensitivity, compared to normal levels (Table 2).

Importantly, the reduction or absence in laryngeal sensitivity may lead to laryngeal penetration and/or tracheal silent aspiration. It has been reported that stroke patients exhibited reduced sensitivity contributing to laryngeal or tracheal aspiration (27).

Pharyngeal residue and epiglottic valleculae associated with pyriform recesses occurred in the present study, with the incidence being highest in cerebral cortex lesions for all food consistencies. These data differ from a report of a lower incidence of pharyngeal residue in epiglottic valleculae and/or pyriform recesses in cortical brain injury (9).

No relationship between waste and pharyngeal clearance of food waste based on consistency and type and location of injury was found in the literature.

There was no laryngeal penetration and tracheal aspiration in most stroke patients, independent of injury location and type in all food consistencies.

Subcortical stroke was the only injury location in which there was laryngeal penetration and tracheal silent aspiration for all food consistencies. Thus, we stress the importance of instrumental assessment of swallowing in such cases. Aspiration has been reported in $52.3 \%$ of subcortical stroke patients, but the author did not describe the food consistency evaluated (28).

Throat clearing occurred in all patients in cases of laryngeal penetration and tracheal aspiration, and did not persist in AVEH, widening cases of stroke, and TIA.

\section{CONCLUSIONS}

This study correlated brain injury with dysphagia in stroke patients, which persisted in ischemic and cerebral cortex strokes.

In the clinical evaluation of swallowing function, oral dysphagia was predominant in patients with lesions in the cerebral cortex and subcortical areas and ischemic stroke. An FOIS ${ }^{\circledast}(16)$ score of 7 was predominant for lesions in the cerebral cortex and ischemic stroke.

In FEES $^{\circledast}$ (17), decreased laryngeal sensitivity predominated in patients with lesions in the cerebral cortex and ischemic stroke. Intraoral posterior escape persisted for all food consistencies when lesions were located in the cerebral cortex and subcortical areas. Pharyngeal residue in epiglottic valleculae associated with pyriform recesses predominated in the cerebral cortex for all food consistencies and in ischemic stroke.

In subcortical strokes, there was no reduction of pharyngeal residue, which was prevalent in ischemic stroke; laryngeal penetration and tracheal aspiration, and silent aspiration with no laryngeal sensitivity occurred.

A Severity Scale: Penetration and Aspiration (18) score of _ predominated in patients with lesions in the cerebral cortex and ischemic stroke. 


\section{REFERENCES}

1. Benseñor I, Lotufo P. A incidência do acidente vascular cerebral no Brasil. Disponível em: http:// saude.hsw.uol.com.br/avc-epidemiologia.htm

2. Furkim A, Mattana A. Fisiologia da deglutição orofaríngea. In: Ferreira L, Befi-lopes D, Limonge S. Tratado de fonoaudiologia. $1^{\underline{a}}$ ed. São Paulo: Rocca; 2004, pp. 212218.

3. Michou E, Hamdy S. Cortical input in control of swallowing. Curr Opin Otolaryngol Head Neck Surg, 2009; 17:166-171.

4. Rosado C, Amaral L, Galvão AP, Guerra S, Furia C. Avaliação da disfagia em pacientes pediátricos com traumatismo crânio-encefálico. Rev. CEFAC, 2005; 7:34-41.

5. ASHA: American Speech and Hearing Association. Model medical review guidelines for dysphagia services [monograph on the Internet] 2004 (Revision to DynCorp 2001 FTRP by ASHA). (cited 2007 Mar 3). Available from: http://www.asha.org/NR/rdonlyres/5771B0F7- D7C04D47-832A 86FC6FEC2AE0/0/DynCorpDysph.

6. Palmer J, Duchane A. Rehabilitation of swallowing disorders due to stroke. Phys Med Rehabil Clin N Amer, 1991; 2:529-536.

7. Pacianori M, et al. Dysphagia following stroke. Euro Neurol, 2004; 51:162-167.

8. Schelp A, Cola PC, Gatto A, Silva RG, Carvalho L. Incidência de disfagia orofaríngea após acidente vascular encefálico em hospital público de referência. Arq Neuropsiquiatr, 2004; 62:503-506.

9. Bassi A, Mitre E, Silva M, Arroyo M, Pereira M. Associação entre disfagia e o topodiagnóstico da lesão encefálica pósacidente vascular encefálico. Rev. CEFAC, 2004; 6:135-142.

10. Miguel J. Análise comparativa da deglutição no AVEagudo de tronco encefálico e supratentorial. Minas Gerais, 2010, p. 75, (Trabalho de Conclusão de Curso de Fonoaudiologia da Faculdade de Medicina da Universidade Federal de Minas Gerais).

11. Xerez D, Carvalho Y, Costa M. Estudo clínico e videofluoroscópico da disfagia na fase subaguda do acidente vascular encefálico. Radiol Bras, 2004; 37:9-14.

12. O'Sullivan S, Schmitz T. Fisioterapia avaliação e tratamento, $2^{a}$ ed. São Paulo: Manole; 1993, pp. 385.
13. Hudak C, Gallo B. Cuidados intensivos de enfermagem: uma abordagem holística, $6^{\underline{a}}$ ed. Rio de Janeiro: Guanabara Koogan; 1997.

14. Marik P. Aspiration pneumonitis and aspiration pneumonia. N Engl J Med, 2001; 344:665-671.

15. American Dietetic Association (ADA). Food and nutrition misinformation: position of ADA. J Am Diet Assoc, 2002; 102260-266.

16. Crary M, Mann G, Groher M. Initial psychometric assessment of a functional oral intake scale for dysphagia in stroke patients. Am J Phys Med Rehab, 2005; 86:15161520 .

17. Langmore S, Schatz K, Olsen N. Fiberoptic endoscopic examination of swallowing safety: a new procedure. Dysphagia, 1988; 2:216-219.

18. Rosenbek J, Robbins J, Roecker E, Coyle J, Woods J. A penetration aspiration scale. Dysphagia, 1996; 11:93-98.

19. Gomes G. Identificação de fatores preditivos de pneumonia aspirativa em pacientes hospitalizados com doença cerebrovascular complicada por disfagia orofaríngea. Curitiba, 2001, p. 86, (Tese Doutorado - Setor de Ciências da Saúde, da Universidade do Paraná).

20. Martino R, Foley N, Bhogal S, Diamant N, Speechley M, Teasell R. Dysphagia after stroke: Incidence, diagnosis and pulmonary complications. Stroke, 2005; 36:2756-2763.

21. Carr J, Shepherd R. Mudando a face da reabilitação neurológica. Rev Bras Fisioter, 2006; 10:147-156.

22. Silvia R. Disfagia neurogênica em adultos pós-acidente vascular encefálico: identificação e classificação. São Paulo, 1997, (Dissertação de Mestrado. São Paulo: Universidade Federal de São Paulo).

23. Almeida É. Frequência e fatores relacionados à disfagia orofaríngea após acidente vascular encefálico. Belo Horizonte, 2009, p. 65, (Dissertação apresentada ao Instituto de Ciências Biológicas da Universidade Federal de Minas Gerais).

24. Silva RG, Jorge A, Peres F, Cola P, Gatto A, Spadotto A. Protocolo para controle de eficácia terapêutica em disfagia orofaríngea neurogênica (PROCEDON). Rev. CEFAC, 2010; 12:75-81.

25. Veis S, Logemann J. Swallowing disorders in persons with cerebrovascularaccident. Arch Phys Med Rehabil, 1985; 66:372-375. 
26. Buchholz D, Robbins J. Neurologic diseases affecting oropharingeal swallowing. In: Perlman A, Schulze-delrieu K. Deglutition and its discords. San Diego: SingularPublishing Group; 1997.

27. Aviv J, et al. Supraglottic and pharyngeal sensory abnormalities in stroke patients with dysphagia. Ann Otol Rhinol Laryngol, 1996; 105:92-97.

28. Ding R, Logemann J. Pneumonia in stroke patients: a retrospective study. Dysphagia, 2000; 15:51-57. 